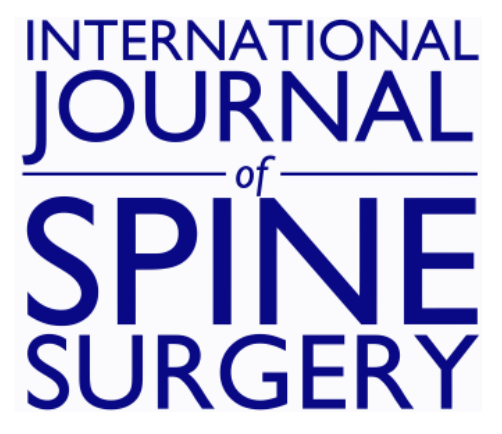

\title{
Elective Lumbar Spine Surgery in Depressed Patients: Is it Worth it?
}

Gemma Vilà-Canet, Augusto Covaro, Anna Isart, David Cáncer, Francesco Ciccolo, Ana García de Frutos, Maite Ubierna and Enric Cáceres

Int J Spine Surg 2021, 15 (3) 418-422

doi: https://doi.org/10.14444/8062

http://ijssurgery.com/content/15/3/418

This information is current as of April 25, 2023.

Email Alerts Receive free email-alerts when new articles cite this article. Sign up at: http://ijssurgery.com/alerts 


\title{
Elective Lumbar Spine Surgery in Depressed Patients: Is it Worth it?
}

\author{
GEMMA VILÀ-CANET, MD, PHD, AUGUSTO COVARO, MD, ANNA ISART, MD, PHD, \\ DAVID CÁNCER, MD, FRANCESCO CICCOLO, MD, ANA GARCÍA DE FRUTOS, MD, \\ MAITE UBIERNA, MD, ENRIC CÁCERES, MD, PHD \\ ICATME (Institut Català Traumatologia i Medicina Esportiva), Institut Universitari Quirón-Dexeus, Universitat Autònoma de Barcelona, Barcelona, Spain
}

\begin{abstract}
Background: The objective of this study is to compare surgical results (pain, function, and satisfaction) between a group of depressed patients and a nondepressed group who had been operated on for a degenerative lumbar condition.

Methods: Prospective observational study. Preoperative pain (lumbar and radicular visual analog scale [VAS]), function (Oswestry Disability Index [ODI]), and depression (Zung depression scale) data were collected in patients listed to be operated on for a lumbar degenerative condition. One year postoperatively, ODI and VAS data were collected again as well as a satisfaction question (are you satisfied with the surgical results? Yes/no).

Results: Ninety-seven patients were included in the study, 78 nondepressed patients $(80.4 \%)$ and 19 depressed patients $(19.6 \%)$. Preoperatively, depressed patients had more lumbar pain $(P=.00)$ and more functional limitation $(P=$ $.01)$ than nondepressed patients. One year postoperatively, depressed patients had more radicular pain $(P=.029)$ and more functional limitation $(P=.03)$ than non-depressed patients. The overall improvement of pain and function was similar between both groups (not significant). Seventy percent of depressed patients and $80 \%$ of nondepressed patients were satisfied with the surgical outcome $(P=.52) 1$ year postoperatively.

Conclusion: Depressed patients experience the same overall level of improvement as nondepressed patients, despite having more pain and functional limitation preoperatively and 1 year after elective lumbar spine surgery than nondepressed patients. The level of satisfaction does not differ significantly between the two groups.
\end{abstract}

Level of Evidence: 2.

Lumbar Spine

Keywords: lumbar spine, elective surgery, depression, outcomes, satisfaction

\section{INTRODUCTION}

Unspecified low back pain is a very common cause of disability worldwide, ${ }^{1}$ and the estimated costs related to this have increased dramatically in the last few years. ${ }^{2}$ Most people with nonspecific low back pain are successfully managed with nonsurgical treatment. However, some of these patients with persistent pain are offered different types of lumbar spine surgery. ${ }^{3}$

It is important to recognize and select appropriate candidates for a foreseeable significant surgical success, which, in itself, is a complex, multifactor construction of subjective and objective variables.

Symptoms of preoperative anxiety and depression occur in approximately one third of chronic back pain patients undergoing surgery and are found to be common in chronic back pain patients in general. ${ }^{4,5}$
Many articles with contradictory results have been published that assessed the impact of depression on the final outcomes of a lumbar surgery for a degenerative condition. Some authors found increased pain and postoperative disability in depressed patients. ${ }^{6-11}$ Katz et al ${ }^{12}$ found an association between depression and more postoperative dissatisfaction 6 months after spinal stenosis surgery. Two years later, the same group published a follow-up of the same sample and found that the preoperative depression score was associated with worse satisfaction. ${ }^{13}$

Some other authors did not find any relationship between depression and surgical results. ${ }^{14-16}$ Elsamadicy et $\mathrm{al}^{14}$ did not find differences in complication rates, walking abilities, and visual analog scale (VAS) scores between patients with and without depression when a sample of patients with a deformity diagnosis was studied. 
The objective of the present study was to assess the surgical outcomes (according to VAS, Oswestry Disability Index (ODI), and a satisfaction questionnaire) in depressed and nondepressed patients who were operated on for a degenerative condition of the lumbar spine. The initial hypothesis was that depressed patients benefit from surgery in a similar way to nondepressed patients.

\section{METHODS}

A prospective observational study was performed in a single hospital and included patients listed to be operated on for a lumbar degenerative condition between September 2014 and April 2016 that agreed to be included in the study.

The inclusion criteria were patients older than 18 years old that needed surgery at one or two levels and required instrumentation or not for a degenerative condition of the lumbar spine. Diagnosis included disc herniation, degenerative disc disease, degenerative spondylolisthesis, or canal stenosis. Surgery was proposed when all conservation measures had failed. First surgeries and reoperations were both included if reoperation was for a different condition than the present procedure.

Patients requiring surgery for a fracture, infection, or tumor were excluded, as were patients requiring long fusions (more than two levels) and those who refused to participate.

Age, sex, surgical procedure, and first surgery or reoperation were recorded at the baseline in addition to standardized, functional pain and depression self-administered tests, including a VAS (lumbar and radicular VAS) ${ }^{17,18}$ and ODI, ${ }^{19-21}$ which is the most widely used back-specific disability questionnaire. Scores ranged from 0 to 100 , where, according to the original publication, 0-20 indicates minimal, 20-40 indicates moderate, and 40-60 indicates severe disability. More than 60 points indicates severe impairment or even exaggerating the symptoms. Finally, a Zung depression scale (ZDS) ${ }^{22,23}$ was also assessed and consisted of a 20 -item self-administered questionnaire, which is already validated in orthopedic surgery and has been used in previously published similar studies. $^{8,24,25}$ The scale ranges from 0 to 100 , and depression is considered when 50 points or more are obtained.

One year after the surgical procedure and after the outpatient visit, a self-administered set of questions was also collected, including ODI, lumbar
Table 1. Surgical procedure performed.

\begin{tabular}{lrc}
\hline Surgical Procedure & $\boldsymbol{n}$ & Percentage \\
\hline Discectomy, $N=25$ & 2 & 25.8 \\
$\quad$ Depressed & 23 & \\
$\quad$ Nondepressed & & 47.5 \\
One-level arthrodesis, $N=46$ & 12 & \\
$\quad$ Depressed & 34 & 12.3 \\
$\quad$ Nondepressed & & \\
Two-level arthrodesis, $N=12$ & 4 & 14.4 \\
$\quad$ Depressed & 8 & \\
$\quad$ Nondepressed & & \\
Laminectomy without fusion, $N=14$ & 1 & 100 \\
$\quad$ Depressed & 13 & \\
$\quad$ Nondepressed & & \\
Total & & \\
\hline
\end{tabular}

and radicular VAS, and a satisfaction question (are you satisfied with surgical results?). Possible responses were yes or no.

\section{Statistical Analysis}

Continuous variables were expressed as mean and standard deviation. Categorical variables were described using frequencies and percentages. The Wilcoxon test was used to compare lumbar/radicular VAS and ODI preoperatively and 1 year after surgery. The $U$ Mann-Whitney test was used to compare ZDS with VAS and ODI. Finally, a Fisher's exact test was used to find the relationship between ZDS and satisfaction.

$P$ values of less than .05 were considered statistically significant. Statistical analysis was performed using the SPSS version 12.0 software (SPSS Inc., Chicago, Illinois, USA).

\section{RESULTS}

One hundred and thirteen patients were initially enrolled in the study, but 16 of them had to be excluded because the ZDS was incorrectly fulfilled, so 97 patients were included. Fifty-four $(56 \%)$ were men and $43(44 \%)$ were women. The average age was 56 years old (range, 21-80). Seventy-eight patients were nondepressed $(80.4 \%)$, and 19 had obtained a score of at least 50 points in the ZDS, so $19.6 \%$ of the sample had a diagnosis of depression. No differences according to age and sex were found between the two groups. Table 1 shows the surgical procedure performed, differentiating the number of depressed and nondepressed patients in each procedure.

Sixty-nine patients $(71.4 \%)$ were operated on for the first time, and 28 patients had previously been operated on for a different condition. 
Table 2. Means and standard deviation of preoperative visual analog scale (VAS) and Oswestry Disability Index (ODI) values comparing depressed and nondepressed patients.

\begin{tabular}{lccc}
\hline & Preoperative Lumbar VAS & Preoperative Radicular VAS & Preoperative ODI \\
\hline Nondepressed, mean (SD) & $6.67(2.99)$ & $7.06(3.19)$ & $38.52(18.32)$ \\
Depressed, mean (SD) & $8.55(1.70)$ & $7.76(2.84)$ & $51.94(20.89)$ \\
$P$ value & .00 & n.s. & .01 \\
\hline
\end{tabular}

Abbreviations: n.s., not significant; SD, standard deviation.

Table 2 shows the preoperative lumbar and radicular VAS and ODI results comparing depressed and nondepressed patients. Depressed patients have higher scores of lumbar VAS and ODI than nondepressed patients.

One year after the surgery, both groups significantly improved their lumbar VAS $(P=.00)$, radicular VAS $(P=.00)$, and ODI $(P=.00)$. Table 3 shows more detailed postoperative results. $\mathrm{Pa}-$ tients in the depressed group have more radicular pain and dysfunction than nondepressed patients 1 year after the surgery.

In Table 4, a difference score (postoperative values - preoperative values) was used to represent the improvement of pain and functional limitation as a result of surgery comparing depressed with nondepressed patients. The difference score is similar between groups in all of the three items measured. The depressed group, despite having worse initial and final values of pain and dysfunction, improved in a similar proportion to the nondepressed group.

No statistically significant relationship was found between satisfaction and depression, and $80.3 \%$ of the nondepressed group were satisfied with the procedure while $70.6 \%$ of the depressed group were satisfied (not significant).

\section{DISCUSSION}

The main finding of this study is that depressed and nondepressed patients improve similarly when a surgery for a degenerative lumbar condition is performed. Satisfaction levels with the procedure were found to be similar in both groups, so the initial hypothesis is confirmed.
The results of the present study show a prevalence of depression similar to that already published. The literature shows a prevalence of depression ranging from $20 \%$ to $30 \%$ in patients with chronic low back pain. ${ }^{26,27}$ In the study presented here, the prevalence is $19 \%$.

The results of the present data stand in line with results published by Wahlman et al. ${ }^{15}$ They studied the prevalence of depressive symptoms preoperatively and 1 year after lumbar spine fusion surgery. They found that prevalence of depressive symptoms decreased after the surgery, and, similar to our results, the level of pain and functional impairment was higher in the depressed group, but it improved significantly with the procedure. Similar results have recently been published by Wagner et $\mathrm{al}^{16}$ in a lumbar degenerative surgery study. They found that patients suffering from pronounced psychological distress preoperatively may significantly benefit from surgery.

However, some authors reported a high dissatisfaction rate with surgery for spinal stenosis ${ }^{13,28}$ when depression is a concomitant factor. Adogwa et $\mathrm{al}^{8}$ stated that the extent of preoperative depression influenced the reported patient satisfaction after revision lumbar surgery in a negative way. The fact that this is a revision surgery study and does not include first procedures could make it noncomparable to our study data. In line with Adogwa, other studies $^{9-11}$ found that depression was a negative predictor for successful surgical outcomes. However, in some of these studies, they did not consider the overall improvement of different outcomes and just took into account the final values obtained. ${ }^{9,10}$ In our series, it can be observed that the initial and final outcomes were worse in depressed patients, but

Table 3. Means and standard deviation at final follow-up of visual analog scale (VAS) and Oswestry Disability Index (ODI) values comparing depressed and nondepressed patients.

\begin{tabular}{lcc}
\hline & Postoperative Lumbar VAS & Postoperative Radicular VAS \\
\hline Nondepressed, mean (SD) & $3.37(2.67)$ & $1.38(2.33)$ \\
Depressed, mean (SD) & $4.32(2.90)$ & $2.74(3.05)$ \\
$P$ value & n.s. & .02 \\
\hline
\end{tabular}

Abbreviations: n.s., not significant; SD, standard deviation. 
Vilà-Canet et al.

Table 4. Difference score (postoperative - preoperative) values of visual analog scale (VAS) and Oswestry Disability Index (ODI) values comparing depressed and nondepressed patients.

\begin{tabular}{lccc}
\hline & Difference Score Lumbar VAS & Difference Score Radicular VAS & Difference Score ODI \\
\hline Nondepressed, mean (SD) & $-3.34(3.43)$ & $-5.76(3.68)$ & $-17.2(24.16)$ \\
Depressed, mean (SD) & $-4.23(3.12)$ & $-5.02(3.72)$ & $-21.5(28.38)$ \\
$P$ value & n.s. & n.s. & n.s. \\
\hline
\end{tabular}

Abbreviations: n.s., not significant; SD, standard deviation.

the overall improvement was similar in both groups, suggesting that the benefits obtained by depressed patients do not differ from those obtained by nondepressed patients. This fact could explain high levels of satisfaction in both groups.

Recently, Strom et $\mathrm{al}^{29}$ published a systematic review recommending tips to improve anxiety and depression in the preoperative and postoperative period to optimize surgical outcomes. They found a relationship between the quality and quantity of information they gave to the patient and the level of anxiety and depression. Similar results were stated by Trief et al. ${ }^{25}$ In this author's opinion, it is essential to transmit adequate, understandable information that generates adequate expectations for the procedure. It is also important to identify patients with depressive symptoms preoperatively so that they can be treated before surgery to optimize surgical outcomes.

A limitation of this study is that we must remember that the diagnosis of depression is complex, and we have simplified it with a selfadministered test, but studies similar to ours also use these questionnaires. A second limitation is the great diversity of questionnaires that exist, making it difficult to compare between them. The discrepancy in the number of patients should also be taken into consideration; there are many fewer depressed patients. Finally, the inclusion of different degenerative lumbar disorders and different diagnoses in the same study group could also be a limitation.

\section{CONCLUSIONS}

The presence of depressive symptoms should not make us exclude elective surgery of the lumbar spine at one or two levels. The overall improvement in the different outcomes studied will not differ significantly from the group without depression. Finally, satisfaction observed does not differ significantly between both groups, although depressed patients are $10 \%$ less satisfied.

\section{REFERENCES}

1. Global Burden of Disease Study 2013 Collaborators. Global, regional, and national incidence, prevalence, and years lived disability for 301 acute and chronic diseases and injuries in 188 countries, 1990-2013: a systematic analysis for the Global Burden of Disease Study 2013. Lancet. 2015;386(9995):743-800.

2. Martin BI, Deyo RA, Mirza SK et al. Expenditures and health status among adults with back and neck problems. JAMA. 2008;299(6):656-664.

3. Croft PR, MacFarlane GJ, Papageorgiou AC et al. Outcome of low back pain in general practice: a prospective study. BMJ. 1998;316(7141):1356-1359.

4. Arts MP, Kols NI, Onderwater SM et al. Clinical outcome of instrumented fusion for the treatment of failed back surgery syndrome: a case series of 100 patients. Acta Neurochir. 2012;154(7):1213-1217.

5. Falavigna A, Righesso O, Teles AR et al. Depression subscale of the Hospital Anxiety and Depression Scale applied preoperatively in spinal surgery. Arq Neuropsiquiatr. 2012;70(5):352-356.

6. Sinikallio S, Aalto T, Airaksinen O et al. Depression is associated with poorer outcome of lumbar spinal stenosis surgery. Eur Spine J. 2007;16(7):905-912.

7. Tetreault L, Nagoshi N, Nakashima $\mathrm{H}$ et al. The impact of depression and bipolar disorders on functional and quality of life outcomes in patients undergoing surgery for degenerative cervical myelopathy: analysis of a combined prospective data set. Spine (Phila Pa 1976). 201742(6):372-378.

8. Adogwa O, Parker S, Shau D et al. Preoperative Zung depression scale predicts patient satisfaction independent of the extent of improvement after revision lumbar surgery. Spine $J$. 2013;13(5):501-506.

9. Chapin L, Ward K, Ryken T. Preoperative depression, smoking and employment status are significant factors in patient satisfaction after lumbar spine surgery. Clin Spine Surg. 2017;30(6):E725-E732.

10. Celestin J, Edwards RR, Jamison RN. Pretreatment psychosocial variables as predictors of outcomes following lumbar surgery and spinal cord stimulation: a systematic review and literature synthesis. Pain Med. 2009;10(4):639-653.

11. Trief PM, Grant W, Fredrickson BA. Prospective study of psychological predictors of lumbar outcome. Spine (Phila Pa 1976). 2000;15;25(20):2616-2621.

12. Katz JN, Lipson SJ, Brick GW et al. Clinical correlates of patient satisfaction after laminectomy for degenerative lumbar spinal stenosis. Spine (Phila Pa 1976). 1995;15;20(10):11551160 .

13. Katz JN, Stucki G, Lipson SJ et al. Predictors of surgical outcome in degenerative lumbar spinal stenosis. Spine (Phila Pa 1976).1999;24(21):2229-2233.

14. Elsamadicy AA, Adogwa O, Sergesketter AR et al. Relationship between Koenig depression scale and post- 
operative outcomes, ambulation and perception on pain in elderly patients undergoing elective spinal surgery for adult scoliosis. World Neurosurg. 2017107:471-476.

15. Wahlman $\mathbf{M}$, Hakkinen A, Dekker $\mathbf{J}$ et al. The prevalence of depressive symptoms before and after surgery and its association with disability in patients undergoing lumbar spinal fusion. Eur Spine J. 2014;23(1):129-134.

16. Wagner A, Shiban Y, Wagner C et al. Psychological predictors of quality of life and functional outcome in patients undergoing elective surgery for degenerative lumbar spine disease. Eur Spine J. 2020;29(2):349-359.

17. von Kolff M, Jensen MP, Karoly P. Assessing global pain severity by self-report in clinical and health services research. Spine (Phila Pa 1976). 2000;15;25(24):3140-3151.

18. Serrano-Atero MS, Caballero J, Cañas A, Gracía-Saura PL. Valoración del dolor (I). Rev Soc Esp Dolor. 2002;9:94-108.

19. Fairbank JC, Couper J, Davies JB. The Oswestry low back pain questionnaire. Physiotherapy. 1980;66(8):271-273.

20. Fairbank JC, Pynsent PB. The Oswestry disability index. Spine (Phila Pa 1976). 2000;25(22):2940-2953.

21. Flórez Garcia MT, García Pérez MA, García Pérez F. Adaptación transcultural a la población espanyola de la escala de incapacidad por dolor lumbar de Oswestry. Rehabilitación. 1995;29:138-145.

22. Zung WW, Richards CB, Short MJ. Self-rating depression scale in an outpatient clinic. Further validation of the SDS. Arch Gen Psychiatry. 1965;13(6):508-515.

23. Conde V. Escala autoaplicada de depresión de Zung. Arch Neurobiol. 1969;32(4):535-558.

24. Arpino L, Iavarone A, Parlato C, Moraci A. Prognostic role of depression after lumbar disc surgery. Neurol Sci. 2004;25(3): 145-147.

25. Li S, Qi M, Yuan W. The impact of the depression and anxiety on prognosis of cervical total disc replacement.Spine (Phila Pa 1976)2015;40(5):E266-E271.

26. Trief PM, Ploutz-Snyder R, Fredrickson BE. Emotional health predicts pain and function after fusion: a prospective multicenter study. Spine (Phila Pa 1976). 2006;31(7):823-830.

27. Carreon LY, Glassman SD, Djurasovic M et al. Are preoperative health-related quality of life scores predictive of clinical outcomes after lumbar fusion? Spine (Phila Pa 1976). 2009;34(7):725-730.

28. Silvers HR, Lewis PJ, Asch HL. Decompressive lumbar laminectomy for spinal stenosis. J Neurosurg. 1993;78(5):695701.

29. Strom J, Bjerrum MB, Nielsen CV et al. Anxiety and depression in spine surgery - a systematic integrative review. Spine J. 2018;18(7)1272-1285.

Disclosures and COI: No conflict of interest to declare.

Corresponding Author: Gemma Vilà-Canet, Hospital Universitari Quiron-Dexeus, C/Sabino Arana 5-19, Barcelona 08028, Spain. Phone: 0034 932054362; Email: gvilacanet@gmail.com.

Published 1 June 2021

This manuscript is generously published free of charge by ISASS, the International Society for the Advancement of Spine Surgery. Copyright (C) 2021 ISASS. To see more or order reprints or permissions, see http://ijssurgery.com. 